\title{
Profissionalização Docente: uma Leitura Piagetiana de sua Construção
}

\section{Cilene Ribeiro de Sá Leite Chakur}

Universidade Estadual Paulista (Unesp)/ Campus de Araraquara

Apresenta reflexões acerca da formação continuada do professor, visando, a longo prazo, contribuir para a formulação de uma teoria do desenvolvimento profissional docente, fundamentada no construtivismo piagetiano. São revisados alguns conceitos e princípios desta corrente, particularmente os relacionados com o processo de tomada de consciência, e discutidos problemas trazidos por uma leitura piagetiana da prática docente. Propõe-se, aofinal, uma hierarquia de níveis de construção da profissional idade docente, tendo como eixos a prática pedagógica, a conquista da autonomia e a identidade profissional do professor.

\section{Introdução}

Pretendemos, neste trabalho, abordar a questão da formação continuada do professor, tendo como pano de fundo a perspectiva piagetiana de análise. E também nossa intenção que as reflexões que vimos fazendo a respeito (Chakur, 1994, 1995a) possam, a longo prazo, contribuir para a formulação de uma teoria da profissionalização docente, recentemente perseguida por vários estudiosos da educação (cf. Nóvoa, 1992; Perrenoud, 1993).

De fato, a prática pedagógica vem sendo atualmente considerada o eixo central da formação docente, enquanto categoria de atividades que ocorrem em situações que nunca são as mesmas e que são sempre proble- 
máticas. Tem sido igualmente concebida como o espaço próprio da construção de saberes pedagógicos, dado que a atuação em sala de aula é objeto de análise e de interpretação contínuas por parte dos professores.

Alguns estudos têm mostrado que, muito mais que tentar solucionar problemas práticos com o recurso a teorias e técnicas científicas, o professor busca, no decorrer de sua vida profissional, atender às exigências de situações únicas, instáveis e complexas com que se depara diariamente, recorrendo a certa "compreensão em ação". A visão da figura do professor "técnico-especialista" vem sendo, assim, substituída pela do "prático reflexivo" (Schõn, 1992) ou "investigador" (Zeichner, 1992), enquanto a prática, antes percebida como eminentemente técnica ou instrumental, toma-se "investigação na ação".

É esse "veio" que o presente trabalho pretende retomar, partindo, antes de rnais nada, da visão do professor como sujeito ativo e construtor da sua prática, em sentido que é necessário explicitar.

Embora seja a atuação de sala de aula o núcleo da atividade docente, não podemos esquecer que esta é uma atividade de muitas facetas, não se reduzindo apenas ao que se chama aspecto técnico-pedagógico. Ao invés, o professor cumpre funções múltiplas, intimamente imbricadas. Fazem parte do seu papel, por exemplo, o preparo das gerações futuras para o exercício da cidadania (aspecto social); o comprometimento com transformações sociais que assegurem e aperfeiçoem a democracia, incluindo as reivindicações que são próprias da categoria (aspecto político); o saber lidar com personalidades distintas e com conflitos intra e intergeracionais (aspecto psicológico), e o investimento na continuidade da própria formação (aspecto profissional), além do caráter técnico-pedagógico já citado.

Para que a prática docente assuma, pois, o sentido rnais amplo de profissionalidade, constituindo-se, ademais, num fazer-se no tempo (desenvolvimento ou construção), deve ser tomada como toda e qualquer prática que é prerrogativa do professor enquanto profissional do ensino e, como tal, abrangendo todos os seus aspectos ou dimensões.

Tendo em vista nossas intenções de partida, discorreremos, inicialmente, sobre alguns tópicos do construtivismo piagetiano. Em seguida, 
tentaremos fazer uma leitura piagetiana da pratica docente e do seu processo em direção a uma práxis reflexiva, discutindo alguns problemas trazidos por esta análise. Por último, esboçaremos uma proposta que estabelece uma hierarquia de níveis de construção da profissionalidade docente, recorrendo a dados empíricos colhidos ao longo de uma experiência de interação com professores de $5^{\mathrm{a}}$ a $8^{\mathrm{a}}$ série.

Longe de constituir-se em sistematização acabada, achamos que o conjunto das reflexões aqui organizadas pode ser o início de um casamento feliz e duradouro entre a Psicologia Genética piagetiana e uma teoria do desenvolvimento profissional docente.

\section{O construtivismo piagetiano}

Como bem diz o termo, o construtivismo tem como principal pressuposto o de que os conhecimentos próprios do homem não são inatos nem adquiridos exclusivamente em função do meio, mas construídos.

Contrapondo-se à posição inatista, que postula estruturas do conhecimento preexistentes à experiência (origem interna dos conhecimentos), e também à empirista, que as concebe como cópias do real (origem externa), Piaget defende a sua construção (ou reconstrução) é na interação com o objeto que o sujeito constrói formas de pensamento cada vez mais organizadas, melhor elaboradas e adaptadas ao real. O objeto só se torna, então, conhecido quando o sujeito age sobre ele e o transforma.

Esta construção é também um processo de descentraçâo que se aplica tanto ao eu individual, relativamente ao conjunto de perspectivas (chegando às relações de reciprocidade e cooperação) quanto às particularidades do objeto, coordenando-as entre si (aproximando-se da objetividade). Constitui-se, pois, construção do mundo e autoconstruçâo do sujeito em direção à autonomia.

A autonomia, por sua vez, manifesta-se "pela participação irredutível e indispensável do indivíduo na elaboração de novas formas de pensar e novos conhecimentos", como afirma La Taille(1992, p.112), mas 
também se revela no respeito às regras em função de acordos mútuos, nas relações de cooperação em que culminam os intercâmbios com o outro, quando são possíveis a "discussão, troca de pontos de vista, controle mútuo dos argumentos e das provas" (id. ibid., p.19-20).

Quanto às formas de conhecimento de que o homem é capaz, Piaget (1973a) se refere a três formas distintas: conhecimentos estruturados por uma programação hereditária (certas percepções espaciais, como visão das cores e espaço tridimensional, por exemplo), aquisições em função da experiência física (ou F) e aquisições em função da experiência lógicomatemática (ou LM).

Note-se que as duas últimas categorias definem aquisições que dependem da experiência, mas sendo esta de dois tipos distintos. Na experiência $\mathrm{F}$, o sujeito age sobre os objetos e deles retira conhecimentos por abstração física (ou empírica), ou seja, descobre propriedades inerentes à natureza dos objetos (seu peso, forma ou cor, por exemplo). $\mathrm{Na}$ experiência LM, os conhecimentos são retirados não dos objetos, mas das próprias ações (ou coordenação de ações) do sujeito, por abstração lógico-matemática, quando, então, ele descobre ligações introduzidas no objeto por estas ações (de colocar em correspondência, reunir, ordenar, por exemplo).

As ações como acima caracterizadas comportam dois mecanismos opostos, mas solidários, que constituem os componentes de toda adaptação inteligente: a assimilação, que consiste na "incorporação de um elemento exterior (objeto, acontecimento etc.) em um esquema sensório-motor ou conceituai do sujeito" e a acomodação, relativa à "necessidade em que se encontra a assimilação de considerar as particularidades próprias dos elementos a assimilar" (Piaget 1975, p.12)'. A acomodação

\footnotetext{
${ }^{1}$ Tratando-se de sistemas cognitivos em geral, com seu caráter de totalidade, e consideradas suas subdivisões, podem ocorrer "assimilações recíprocas" em que subsistemas se assimilam mutuamente e se coordenam entre si, ou quando este processo liga um sistema total e os subsistemas que o integram. O mesmo é válido para o processo de acomodação.
} 
é, portanto, a responsável pela modificação da ação para que esta se ajuste às propriedades particulares do objeto.

Mas uma ação nunca se apresenta totalmente nova. E o que importa, na verdade, não são as ações tomadas isoladamente, mas seu esquema, que Piaget (1973a) define como "o que, numa ação, é assim transponível, generalizável ou diferenciável de uma situação à seguinte, ou seja, o que há de comum nas diversas repetições ou aplicações da mesma ação" (p.16). Tais são os esquemas de agarrar, reunir, separar, etc, que não se confundem com ações particulares, mas resultam de sua generalização, não sendo, pois, perceptíveis.

Além disso, como esclarecem Coll e Gilliéron (1987, p.34), um esquema é um "verdadeiro quadro assimilador que permite compreender a realidade à qual se aplica, atribuindo-lhe significações, é a unidade básica do funcionamento cognitivo e, simultaneamente, o ingrediente elementar das formas de pensamento, desde as rnais simples às rnais complexas e elaboradas". Constituindo-se em unidades assimiladoras nos planos da ação material, da representação e da conceituação, os esquemas tendem a combinar-se e coordenar-se entre si (olhar-e-agarrar, reunir-e-ordenar, por exemplo), organizando-se, enfim, em estruturas rnais gerais do conhecimento.

Uma estrutura, por sua vez, compõe-se de elementos e das relações que os ligam, constituindo-se em "forma", um sistema de relações aos poucos destacado dos conteúdos que lhe servem de "alimento" (particularidades do meio), no transcurso do desenvolvimento intelectual.

Esquemas e estruturas são constantemente organizados e reorganizados durante a história individual, diferenciando-se e integrando-se em estruturas de ordem superior, num processo que imprime ao desenvolvimento a forma de períodos seqüenciais (Sensório-Motor, Operacional Concreto e Operacional Formal) com suas subdivisões em estádios que se sucedem em ordem fixa, mais ou menos independente da idade cronológica. As estruturas construídas em cada etapa permitem ao indivíduo interagir de certo modo com a realidade e compreendê-la em dado nível, 
assim configurando certo estado de equilíbrio nos intercâmbios com o mundo circundante.

Mas cada estado de equilíbrio não é de nenhum modo estático, nem se confunde com um estado de repouso sucessivamente substituído por outro (o que significaria "destruição" de estruturas já elaboradas). É, pois, necessário invocar o mecanismo que produz os vários degraus de equilíbrio: a equilibração - processo pelo qual o sujeito opõe reações compensatórias (regulações) às perturbações sofridas ou antecipadas.

Assim, diante de uma perturbação que é fonte de desequilíbrio, ${ }^{2}$ o sujeito tenta compensá-la mediante regulações que conduzem do resultado da ação a sua retomada, corrigindo-a (feedback negativo) ou reforçando-a (feedback positivo). E no domínio lógico-matemático, as regulações rnais "perfeitas" são as próprias operações reversíveis (regulações de regulações) ${ }^{3}$, com seu duplo caráter proativo (antecipação) e retroativo. Mas esse percurso da equilibração até chegar às regulações de regulações pode exprimir-se em outra linguagem: a das "reflexões".

Assim é que as estruturas cognitivas passam de sensório-motoras a operatórias concretas e, em seguida, formais, mediante um processo que Piaget (Piaget, 1975, Piaget, Coll., 1977) chama de abstraction réfléchissante, com seus dois sentidos de "reflexão": primeiramente, o sujeito reflete (no sentido físico do termo) uma dada ação, projetando-a sobre um novo patamar de ordem superior (por exemplo, o nível dos conceitos

\footnotetext{
${ }^{2}$ As perturbações constituem-se obstáculos aos processos de assimilação e acomodação e podem ser, de um lado, lacunas "que deixam as necessidades insatisfeitas e se traduzem pela insuficiente alimentação de um esquema" e, de outro, causas de fracassos ou de erros — "resistências do objeto, obstáculos às assimilações recíprocas de esquemas ou de subsistemas etc." (Piaget, 1975, p.24). Mas qualquer elemento perturbador só é gerador de conflitos para uma estrutura já ativada. Além disso, nem sempre a reação à perturbação é seguida de regulação. A perturbação pode provocar repetição da ação ou simplesmente a sua parada, desviando-se o sujeito para outra direção. Por sua vez, a regulação pode não se revelar compensatória, como no caso de reforço de um erro.

${ }^{3}$ As operações são ainda ações, mas ações interiorizadas, coordenadas e reversíveis. São, pois, estruturas cognitivas aplicáveis seja a objetos manipuláveis física ou mentalmente (nível concreto), seja ao possível, a hipóteses e proposições (nivel formal).
} 
com relação ao das ações materiais) - projeção esta denominada réfléchissement; em seguida, é necessário integrar esta ação em uma nova estrutura (a que está em vias de construção), reconstruindo sobre este novo patamar os elementos extraídos do anterior ou colocando em relação os elementos oriundos dos dois níveis - reorganização chamada réflexion.

Desse modo, é a união de um novo réfléchissement e de uma nova réflexion que caracteriza a formação de toda nova etapa de desenvolvimento. Isto significa, como esclarece Piaget (1973a, p.361), que "o desenvolvimento de uma estrutura não pode ser feito exclusivamente em seu próprio patamar, por simples extensão das operações dadas e combinação dos elementos conhecidos. O progresso consiste em construir uma estrutura rnais ampla que abranja a precedente, mas introduzindo novas operações". Significa, ademais, que a equilibração não é simples marcha para o equilíbrio, mas é em geral orientada para um melhor equilíbrio, assim caracterizando a equilibração majorante.

Mas Piaget alerta que, embora presente em todos os estádios do desenvolvimento, a abstração réfléchissante só se torna consciente no nível das operações formais, quando o sujeito é capaz de "tematização retroativa" ou reflexão sobre a reflexão (capaz, portanto, de uma "teoria"). É então que a abstração passa a ser refletida (réfléchie), alcançando o nível do pensamento reflexivo propriamente dito.

Tendo em vista o modelo construtivista piagetiano assim resumido, resta perguntar se as construções cognitivas de que o homem é capaz se estabilizam sempre em conhecimentos válidos e coerentes. Não existiria aí a possibilidade de deformações, por exemplo? Ou estas seriam próprias apenas dos estádios elementares do pensamento infantil, sendo estranhas ao adulto? Estas são algumas das questões levantadas pelo problema da tomada de consciência, que nos interessa particularmente.

Certas categorias de ação se reduzem a um simples "fazer" material. Mas do mesmo modo que a ação pode ou não chegar a um "saber fazer", ou fazer com êxito, também pode ou não conduzir ao conhecimento, no sentido de compreensão. 
Em obra a respeito, Piaget (1978) diferencia claramente o saber fazer, que consiste em "compreender em ação uma dada situação em grau suficiente para atingir os fins propostos", do compreender, que é "conseguir dominar, em pensamento, as mesmas situações até poder resolver os problemas levantados em relação ao porquê e ao como das ligações constatadas e, por outro lado, utilizadas na ação" (p.176). Em outras palavras, compreender "consiste em isolar a razão das coisas, enquanto saber fazer é somente utilizá-las com sucesso" (p.179).

Por outro lado, toda atividade humana exige algum grau de consciência. Na concepção piagetiana, a consciência pode revelar-se "elementar ou periférica", quando se aplica a dados imediatamente percebidos, aos objetivos da ação e aos seus resultados enquanto êxito ou fracasso (elementos pertencentes à "periferia" da consciência e, como tais, facilmente conscientes). Mas a consciência pode igualmente chegar à compreensão. Para tanto, é necessário o recurso à tomada de consciência que, não sendo de nenhum modo um processo de "iluminação", caminha em duas direções complementares: consciência das propriedades intrínsecas dos objetos e de suas relações causais (ou "processo de exteriorização", que corresponde à construção do real); e consciência dos mecanismos centrais da ação mesma do sujeito ("processo de interiorização", correspondente à estruturação do pensamento).

São muitos os exemplos encontrados no cotidiano, em que agimos sem que seja necessária a tomada de consciência: não procuramos saber, por exemplo, o porquê e o como das atividades de nos levantarmos pela manhã, nos locomovermos e nos banharmos. Ações como essas não requerem compreensão para terem êxito. Os reforços ou correções eventuais são rnais ou menos imediatos e dizemos que são ações dominadas por regulagens automáticas, determinadas de fora "por uma seleção progressiva dos movimentos que aproximam a ação de seu objetivo, mas sem que haja intervenção de escolha deliberada ou intencional por parte do sujeito" (Piaget, 1977, p.127). Nesses casos, a tomada de consciência nada acrescentaria, provavelmente, à eficiência da ação. 
Mas há certas ações cujas coordenações não rnais dão conta dos dados presentes naquele momento, e o sujeito é levado a mudar de meio ou hesitar entre vários. Tais casos comportam, então, regulações ativas, em que intervém escolhas deliberadas, sendo necessária a consciência. É, portanto, a consciência dos meios que torna possível a reconstrução do saber fazer no plano da compreensão.

Lembremos, contudo, que a conscientização não ocorre mecanicamente, nem de modo imediato. E também que é um processo que pode aplicar-se seja ao observável presente nos objetos ou na própria ação (o que o sujeito crê constatar por uma leitura imediata da experiência), seja às relações e coordenações (entre observáveis ou entre ações). Ficaremos apenas com o caso dos observáveis, que já é significativo.

Tratando-se dos observáveis sobre o objeto, há situações em que o sujeito "vê" certas qualidades que não correspondem aos caracteres reais do objeto, porque aplicou uma qualidade por engano, ou porque as propriedades retidas permanecem incompletas. Daí, as deformações resultantes. Mas o conteúdo perceptível continua povoado de observáveis em potencial, "resistindo" à pressão dos esquemas de assimilação.

No caso de observáveis sobre a ação, são comuns (e típicas da ação sensório-motora) as situações em que conseguimos êxito em nosso desempenho, mas não sabemos como isto se deu, não podemos explicálo. E por muito tempo podemos rejeitar ou negligenciar aspectos da nossa ação, porque não se "encaixam" em nossa compreensão habitual, porque contradizem, portanto, o esquema de representação de que dispomos no momento. Segundo Piaget a "forma" representativa ou conceituai tende a exercer uma espécie de "recalcamento cognitivo" sobre o conteúdo material, impedindo a compreensão. Mas também reciprocamente, e do mesmo modo que no caso dos objetos: os observáveis sobre a ação continuam presentes em estado latente ou virtual (por exemplo, esquemas utilizados de maneira sensório-motora mas não representados) e exercem pressão contrária no sentido de "minar" o esquema recalcado. 
Em ambos os casos, os aspectos observáveis, mas não realmente constatados, permanecendo em campo, constituem-se fator potencialmente perturbador, exercendo pressão no sentido de serem integrados ao esquema representativo ou conceituai pertinente no momento. E essa integração vai ser obra da tomada de conhecimento (dos objetos) ou de consciência (da ação), aí inerente o papel das regulações compensatórias.

\section{Desenvolvimento profissional docente e práxis reflexiva:percurso e dificuldades}

A noção de prática diferencia-se bastante, conforme se passe do senso comum às teorias filosóficas ou científicas. E também uma noção variável no tempo.

Avaliamos alguém, por exemplo, como possuindo "senso prático". Julgamos se certa pesquisa tem "aplicação prática". Dizemos de uma decisão que não se mostra "prática". São exemplos de que o senso comum, com a sua atitude natural cotidiana, concebe a atividade prática num sentido pragmático-utilitário, como "um simples dado que não exige explicação", como afirma Vásquez (1986, p.8). Prático "é o ato ou objeto que produz uma utilidade material, uma vantagem, um benefício; imprático é aquilo que carece dessa utilidade direta e imediata" (id. ibid., p.12).

O termo vem do original grego praxis (que se contrapunha a poiésis), com o sentido de ação que nada produz destacado dela mesma, ação com um fim em si mesma. Incorporando-se posteriormente a várias correntes filosóficas, teve invertido seu sentido original: atividade teórico-prática própria do homem, iniciando-se com uma finalidade projetada e chegando a um produto real. E já vemos aí um processo.

É, pois, dessa noção que partiremos para analisar a prática docente (em sentido amplo, embora privilegiando a prática pedagógica).

Apesar de sua especificidade, podemos conceber a prática docente no sentido da ação piagetiana: atividade transformadora, um "agir so- 
bre" intencional, calcado na interação indivíduo-meio e que, além disso, passa por um processo de construção. Mas o que é transformado? Qual a natureza da interação? E como se dá essa construção?

Pensamos que a prática docente não apenas é em si ação transformadora (que modifica também o próprio sujeito), como visa explicitamente à transformação, e no sentido de progresso. O professor age na instância da sala de aula, por exemplo, porque acredita poder modificar o aluno de um "estado" $n$ (não-físico, evidentemente) a outro superior, $n+1$. Se não houvesse essa crença, ou ao menos certa expectativa, seu trabalho não teria sentido (nem social, nem para ele mesmo).

A interação, por sua vez, parece bem rnais complexa no caso do professor: qual seria o "meio" com o qual interage? Espaço da sala de aula (meio físico, portanto)? Classe de alunos (que já é um meio de natureza relacionai, interativa)? A própria relação professor-aluno? Disciplina curricular (mais congruente com um meio lógico-matemático, porém "institucionalizado")?

Dolle (1993, p.36) propõe uma definição interessante de qualquer meio: "em todo meio, seja ele qual for, encontram-se pessoas (ou sujeitos), objetos naturais e artificiais (...), regras institucionais regendo as relações interindividuais e regras de fabrico e de utilização dos objetos pelas pessoas". Mas cada meio apresenta, ao mesmo tempo, "algo de particular e original por causa das pessoas e dos objetos que o compõem - pessoas e relações entre elas e os objetos determinam regras de funcionamento peculiares - e (...) algo de comum no sentido de que será sempre possível encontrar aí esses diferentes componentes em interação" (p.37). Mas existe um complicador. A interação sujeito-meio depende (exceto para o bebê) da representação que o sujeito dispõe desse meio, representação que, segundo Dolle constitui o "meio-para-o-sujeito", distinto de sua materialidade. E aí se inclui a possibilidade de deformações.

Talvez seja possível diferenciar a prática do professor em dois sentidos: enquanto atividade estruturada de um sujeito incidindo num certo 
meio (um meio complexo, difuso, rnais ou menos instável, mas com regras definidas regulando as condutas) — prática inteligente com "função adaptativa", simplesmente; e enquanto atividade que produz conhecimentos — atividade cognitiva, portanto.

E aqui é pertinente a crítica de Dolle (1993) quanto à confusão que se faz entre a atividade da inteligência e seus produtos, os conhecimentos, e entre atividade de conhecimento e atividade em geral. Segundo ele (como para Piaget), inteligência é fundamentalmente adaptação, e toda atividade da inteligência é estruturada. As estruturações da atividade de adaptação da inteligência, que permitem a interação entre sujeito e meio, podem resultar em conhecimentos. Mas a adaptação não utiliza as estruturas da atividade "apenas para obter conhecimentos. Faz isso também para ter prazer, fruição, mudar de hábitos, distrair-se, satisfazer suas necessidades, exercitar o corpo etc. etc." (p.98). Assim, a noção de inteligência, para Dolle, inclui muito mais que conhecimentos.

Aplicando a terminologia de Dolle ao caso do professor, a função rnais propriamente adaptativa do trabalho docente poderia caber à prática pedagógica, tendo como centro a tríade professor/conteúdo escolar/aluno. E qual seria, então, sua atividade cognitiva?

A começar das formas de experiência e conhecimento no âmbito da prática docente, acreditamos que não estão em jogo apenas os tipos físico (F) e lógico-matemático (LM) tais como Piaget os define.

Se pensarmos na atuação docente enquanto atividade de conhecimento, em contraposição ao fazer adaptativo, a experiência $\mathrm{F}$ poderia referir-se ao agir do professor sobre estímulos perceptíveis de ordem física, dando origem à abstração de aspectos tais como os presentes no espaço em que se encontra (sala de aula, ou de professores, do diretor, espaço reservado a assembléias da categoria, etc); nos objetos com que lida (material didático, por exemplo); e nos observáveis das próprias pessoas enquanto "objetos" também físicos desse espaço. A experiência F poderia igualmente incluir estímulos situacionais ou institucionais, como horá- 
rio, periodo do dia, série escolar dos alunos com que o professor trabalha. etc. O professor "sabe", por exemplo, se determinada sala comporta certa classe, se a lousa e o giz de que dispõe prestam-se à atividade que escolheu e quando deve acender a luz ou ligar o ventilador para criar um ambiente adequado.

No tipo LM de experiência, a abstração se daria, como vimos, sobre dados da própria ação docente. Daí a necessidade de reflexão (em todos os sentidos que lhe dá Piaget) para que haja conhecimento novo e, portanto, mudança da prática. Para tanto, a reflexão deveria incidir sobre a "estrutura" da ação docente (e não sobre seus conteúdos, quaisquer que sejam). Neste caso, a seleção de ações futuras se fundaria, não simplesmente sobre o que "deu certo" ou "errado", ou sobre a utilidade dos objetivos já (ou ainda não) perseguidos, mas sobre a validade do próprio processo, sobre o como e o porquê do êxito e do insucesso.

Embora sejam importantes e pertinentes os conhecimentos dos tipos F e LM, julgamos que a cognição do professor sobre sua prática não é exatamente ou apenas F ou LM, mas eminentemente social. Na prática pedagógica, em particular, não está realmente em jogo o critério lógico de verdade/falsidade, do tipo "se eu ensino, então ele aprende". Não existe aí "necessidade lógica". Também não se coloca como central o critério de presença/ausência de alguma propriedade física. Embora seja necessária a presença física da classe, por exemplo, o aluno presente pode estar psicologicamente ausente.

Pensamos que os significados dados pelo professor a sua prática particularmente à pedagógica -, que necessariamente envolve uma relação entre pessoas (seu núcleo, portanto), fundam-se predominantemente em critérios sociovalorativos (cf. Chakur, 1995). Objetos, acontecimentos, pessoas e relações que devem ser "incorporados" (assimilados) à prática são, assim, avaliados pelo professor dentro do continuиm aprovação-desaprovação, recorrendo ao seu valor (positivo ou negativo), que se expressa por certa hierarquia de desejabilidade, importância ou prefe- 
rência, e à crença ou fé. Muito embora sejam avaliações de caráter subjetivo-afetivo, apóiam-se em critérios socioculturalmente dados. Desse modo, as condutas dos alunos e do próprio professor, assim como as interações entre ambos, podem ser avaliadas como "corretas" ou não, desejáveis ou não, preferenciais ou não, e com certas gradações ou no absoluto, dependendo de como são tomadas (e colocadas) as regras institucionais que regem as condutas e relações no espaço escolar.

Assim descrita, pareceria que a prática docente é sempre flexível, maleável, propícia a rápidas construções. Pensamos que existe, sim, construção de esquemas (no sentido piagetiano) no campo da atuação docente, atrelados aos mecanismos de assimilação-acomodação. E tais esquemas podem ser organizados e reorganizados por diferenciação e integração. É comum, por exemplo, o professor diferenciar sua atuação conforme a classe de alunos, ou a disciplina que ministra, ou o material de que dispõe. Assim como é possível que integre certos esquemas de atuação em princípios gerais, aplicáveis a qualquer situação de ensino.

Os esquemas do professor, como os de qualquer sujeito cognoscente, também requerem "alimentos". Mas alimentos especializados, ou seja, todos os "conteúdos" intra ou extra-escolares pertinentes à situação de ensino, ou a sua profissão em geral, provenientes de objetos, pessoas, acontecimentos e relações (incluindo regras institucionais). O professor pode, por exemplo, seguir "pistas" que dão idéia do nível de aprendizagem do aluno, ou que sinalizam os próximos passos de sua ação, ou que apontam para a "melhor" decisão. E essas pistas são assimiladas aos esquemas pertinentes, que darão, por sua vez, significado a outras situações que comportem as pistas originais.

Alguns autores vêem na generalização dessa atribuição de significados ou no agrupamento destes em totalidades mais ou menos homogêneas a indicação de que os professores se guiam por um tipo de conhecimento específico ligado à ação, de natureza tácita, pessoal e assistemática. Tal conhecimento é identificado como "pensamento prático" (Gómez, 
1992), "teoria implicita" (Zeichner, 1992) ou "epistemologia implícita" (Gimeno Sacristán, 1988), mas de todo modo gerado na prática.

Ao comentar sobre a natureza da prática pedagógica, Perrenoud (1993) observa que o professor constantemente enfrenta rotinas, situações estereotipadas às quais responde também de modo estereotipado. Mas existem situações inéditas, em que é necessário improvisar em face da urgência, não há tempo de fundamentar racionalmente sua decisão. O professor recorre, então, ao habitus - "sistema de esquemas de percepção e de ação que não está totalmente sob o controle da consciência" (p.21) —, noção tomada a Bourdieu, bem próxima à do esquema de assimilação de Piaget.

Assim, tanto em situações familiares como naquelas pouco habituais, o professor põe em ação esquemas "rnais ou menos conscientes", mas que funcionam automaticamente. Segundo Perrenoud (op. cit., p.38-39), "A diferença reside no fato de que numa situação habitual a acomodação é mínima e o professor pode comparar a situação com esquemas já existentes. (...) Ao passo que numa situação inédita, nenhum esquema se adequa exatamente. E necessário transpor, diferenciar, ajustar os esquemas disponíveis, coordená-los de uma maneira original". E já vimos que é o mecanismo de acomodação o responsável por mudanças nos esquemas cognitivos.

Segundo ainda Perrenoud, é possível que o professor proceda a um trabalho de compreensão e reinterpretação a posteriori dos acontecimentos do dia e esta releitura da experiência poderia ser "fator de mudança, de reorganização de esquemas se existisse (...) um conflito cognitivo, uma contradição entre as decisões tomadas e uma norma, uma teoria ou uma outra experiência" (p.44) - o que vem de encontro ao papel dos desequilíbrios cognitivos (e das regulações) proposto por Piaget. Mas esta releitura conduz, rnais freqüentemente, à confirmação da prática, denunciando a resistência do professor à mudança.

Já mencionamos que as ações submetidas a regulagens automáticas (como parece ser o caso do habitus) dificilmente chegam à consciência. Por outro lado, se no âmbito do ensino o êxito ou o fracasso - que, 
enquanto resultados, fazem parte da "periferia" da tomada de consciência — podem ser "lidos" rnais prontamente nas notas dos alunos, não ficam absolutamente claras a sua fonte ou origem para o professor: advém do aluno ou dele próprio? A chegada ao como e ao porquê é ainda rnais difícil, pois meios e razões estão imbricados com essa fonte e origem. $\mathrm{E}$ principalmente porque o êxito e o fracasso vêm permeados de afetos e valores: por exemplo, de quem é a "culpa" no caso de fracasso?

Pensamos que uma possível explicação para a resistência à mudança, comum entre professores, estaria justamente no predomínio, em sua prática, de esquemas de ação rígidos e automaticamente regulados, semelhantes aos sensório-motores e aos intuitivos, por oposição aos operatórios, estes sim flexíveis, auto-reguláveis e aplicáveis a situações diferentes e pouco sujeitos à influência de aspectos figurativos (tais como as "pistas" mencionadas atrás). Mas isso não diz tudo. E necessário buscar em que se funda aquela resistência (aos olhos do observador, bem dito) e como pode ser "minada".

Piaget (1973b, p.35) enfatiza que "o pensamento do indivíduo é dirigido por estruturas das quais ele ignora a existência e que determinam, não somente o que ele é capaz ou incapaz de 'fazer' (logo a extensão e os limites de seu poder de resolver problemas), mas ainda o que é 'obrigado' a fazer (logo as ligações lógicas necessárias que se impõem a seu pensamento)".

Mas o inconsciente cognitivo não contém apenas estruturas. $\mathrm{O}$ funcionamento dessas estruturas, e mesmo das rnais simples ações materiais manifestas, em geral, permanece inconsciente aos olhos do sujeito. Raramente nos perguntamos, por exemplo: por que tal objeto ou instrumento serve melhor a tal objetivo ou é rnais facilmente utilizável do que tal outro? Por que esta estratégia se revelou rnais produtiva que aquela? Por que tal procedimento precisou ser modificado nesta experiência e não em outras?

Como, então, tais questões podem chegar à consciência? 
Piaget (1977, p.199) nos ensina que a tomada de consciência parte da periferia para as regiões centrais da ação, ou seja, "a partir do dado de observação relativo ao objeto (resultado falho), o sujeito vai, portanto, procurar os pontos em que houve falha da adaptação do esquema ao objeto; e, a partir do dado de observação relativo à ação (sua finalidade ou direção global), ele vai concentrar a atenção nos meios empregados e em suas correções ou eventuais substituições".

Quanto à razão de alguns esquemas, mesmo sensório-motores, permanecerem inconscientes, Piaget recorre, como vimos, à noção freudiana de recalque. Um esquema permanece inconsciente porque contradiz certas idéias conscientes anteriores e, neste caso, é eliminado pela ação do recalque. Em outras palavras, o esquema é recalcado por não estar integrado num sistema consciente (representativo ou operatório propriamente dito) que, por este fato mesmo (ser consciente), é superior ao esquema objeto de recalque. Mas o próprio recalque (como também a contradição) situa-se no inconsciente. Na situação em que ele opera por exemplo, diante de um problema - não se pensa numa hipótese, afastando-a em seguida. Ao invés, a hipótese é afastada ante? que penetre no campo da consciência. Desse modo, o sujeito não sente a contradição, pois esta não se situa nem na ação inconsciente, nem na consciência, segundo Piaget (1977), mas no "próprio processo da conceituação que caracteriza a tomada de consciência" (p.203).

Desse modo, a tomada de consciência "consiste em fazer passar alguns elementos de um plano inferior inconsciente a um plano superior consciente", o que implica reconstrução (Piaget, 1973b, p.41). Mas ela pode ser inibida e apresentar-se inicialmente deformante e lacunar até que as contradições sejam integradas em novos sistemas. E quando não há necessidade de tomada de consciência de uma ação bem adaptada, é porque esta é submetida a regulagens automáticas.

Refletindo sobre essas idéias no campo da prática docente, encontramos alguns complicadores, quais sejam: 
a) Embora o professor "ative" certos esquemas sensório-motores em sua prática (falar, escutar, escrever, manejar objetos e aparelhos), ele não parte deste nível (sensório-motor), mas principalmente de esquemas representativos (no mínimo);

b) Os esquemas ativados incluem elementos também de natureza social. E assim teríamos, quem sabe, "formas" interativas interpessoais e normativas (ou institucionais) impregnadas de valores;

c) Decorrente de a e b, segue-se que, se os esquemas são principalmente representativos e se os valores interferem, não saberíamos precisar quais esquemas pertenceriam a um "plano inferior" e quais estariam num "plano superior", quando a tomada de consciência está em processo. Não achamos suficientemente convincente a idéia, neste caso específico, de que um plano de organização é superior a outro apenas porque é consciente. Aliás, o próprio Piaget dá exemplo de um esquema (inconsciente) que progrediu para um plano superior acompanhando-se de representação (consciente) também de nível superior ${ }^{4}$;

d) Os observáveis no campo docente (e lembramos que são relativos não só aos objetos, mas também às ações) são igualmente de diversas naturezas ao mesmo tempo. Embora o conteúdo permaneça "povoado de observáveis em potencial enquanto perceptíveis", sua "pressão" sobre as formas (esquemas do professor) para que sejam considerados e superada sua rejeição talvez seja bastante diluída, porque difusa e um tanto "amorfa". Por esta razão, pode ser que a modificação (reorganização) do esquema que está em atividade seja bem rnais difícil, pois supõe "vencer a repres-

\footnotetext{
${ }^{4}$ Piaget também acha que são necessários estudos que explorem mais a questão do inconsciente cognitivo. Para ele (1973b, p.42), não existem conceitos nem representações inconscientes. O inconsciente "é povoado de esquemas sensório-motores ou operatórios já organizados em estruturas (...) Do ponto de vista afetivo, ele está mesmo provido de tendências, de encargos energéticos, logo, de esquemas afetivos ou do caráter, etc.". Cita, em seguida, um exemplo de progresso num tipo de representação ("lembrança-imagem" ou símbolo representativo) em função do aperfeiçoamento do esquema subjacente. Embora seja certo que as imagens guardadas na memória possam ser reorganizadas, ficamos pensando se um símbolo-imagem (representação, portanto) não poderia ser igualmente guardado no inconsciente. Afinal, parte da memória também é inconsciente...
} 
são" que rejeitava osobserváveis latentes a fim de incorporá-los ao novo esquema. E, neste caso, a quebra de resistência do esquema antigo dependeria da consideração de elementos de natureza não apenas cognitiva, mas também sociovalorativa.

De todo modo, acreditamos que podem ocorrer rnais comumente "desequilíbrios e reequilibrações" locais, relativos a situações particulares e a setores limitados da prática docente. A tomada de consciência deve ser também progressiva nesse campo, com momentos de deformação de dados de observação e de recalque da fonte de conflito e tentativas de superá-los. E pode bem ser que o sentimento de culpabilidade ou frustração, freqüente em casos de fracasso em situação ensino-aprendizagem e inconsciente na maior parte das vezes, imprima maior força ao mecanismo de recalque.

Um bom exemplo dessas vicissitudes é quando certas pistas observadas pelo professor são contraditórias com suas expectativas conscientes, há muito construídas. Se as pistas "não se encaixam", podem ser deformadas para que as expectativas continuem verdadeiras. Ou então, estas últimas não estão suficientemente claras e o professor pode "ver" certa pista inabitual como um caso de exceção - o que caracterizaria uma "solução de compromisso", tal como as apontadas por Inhelder, Sinclair e Bovet (1977) na progressão da tomada de consciência.

Assim, também, não são raros os casos de "resistência do conteúdo" aos esquemas assimiladores do professor: alunos desmotivados, com dificuldades de aprendizagem, reprovações, apelos a desvios de função do professor, ausência de recursos didáticos, e muitos outros. Mas se a situação ou o setor de atividade da prática docente mostrarem-se suficientemente relevantes e significativos (e vemos aí novamente a questão valorativa!), as regulações que vão compensar o desequilíbrio podem redundar num certo tipo de "equilibração majorante". Conseqüentemente, haveria mudança estrutural da prática, criadora de novos esquemas e novas ações manifestas - a práxis reflexiva, enfim. 
Conclusão: uma proposta apoiada na experiência

Para melhor esclarecer a análise que fizemos e apresentar nossa proposta quanto ao desenvolvimento profissional docente, passemos à experiência que partilhamos com professores de $5^{\mathrm{a}}$ a $8^{\mathrm{a}}$ série.

Esta experiência iniciou-se em 1987 junto ao Núcleo de Ensino de Araraquara, SP, com um diagnóstico das condições do ensino público de $5^{\mathrm{a}}$ a $8^{\mathrm{a}}$ série, dos seus professores e da clientela de alunos na região. O projeto, como todos os que lhe seguiram ${ }^{5}$, integrava professores daquelas séries, docentes da Unesp e graduandos estagiários, trabalhando em equipe. Embora sejam poucos os professores da rede deste grupo original que ainda permanecem, cerca de $77 \%$ dos 35 participantes da equipe atual (professores de sete disciplinas distintas) vêm acompanhando os projetos há pelo menos três anos.

Em geral, os projetos foram desenvolvidos em encontros semanais, com atividades no Grande Grupo (conjunto de participantes), ou nos grupos-área (segundo a área curricular dos seus membros), ou em grupos heterogêneos (com participantes de todas as áreas). As atividades eram as rnais variadas: debates de temas educacionais gerais, análise de propostas curriculares oficiais ou de textos de disciplinas específicas, seminários temáticos, realização de pesquisas de campo, registro de depoimentos e sua discussão, e socialização, análise e registro de experiências didáticas, além de muitas outras.

O último projeto, realizado em 1992-1993 (cf. Chakur, 1993), trouxe à luz certas tendências que sinalizam etapas no desenvolvimento profissional dos professores da rede, compatíveis com uma sequiência de três momentos que conseguimos visualizar na consecução dos trabalhos até agora.

Num primeiro momento-diagnóstico - constatamos no grupo de professores, entre outras coisas, inexistência de repertório que permitisse formismo, desmotivação e "choradeira" (queixas, lamúrias constantes); e

\footnotetext{
${ }^{5}$ Projetos subvencionados pela Fundunesp.
} 
qualquer mudança (perpetuação de práticas tradicionais de ensino); com desvios de função, com evidentes falhas na identidade profissional (fazer as vezes de "babá", "pai/mãe", "servente", etc).

$\mathrm{O}$ segundo momento - sensibilização à mudança — parece ter sido um "despertar sem freios" na busca de mudanças: pesquisa "cega" e experimentação de alternativas ao modelo tradicional de ensino, autocrítica do próprio trabalho (com o conseqüente afloramento de ansiedades e culpas) e intensificação na socialização de dificuldades e experiências.

O terceiro momento, atual, parece caracterizar-se pela construção da autonomia e da identidade profissional dos professores. São alguns sinais desta etapa as seguintes realizações ou produtos, todos de responsabilidade dos próprios professores: organização de "data-aulas" (banco de registro de aulas ou experiências didáticas) e de bancos de textos por disciplina curricular; formulação e/ou implementação de propostas de distribuição de conteúdos curriculares; confecção/produção de recursos didáticos ou metodológicos em geral (manuais didáticos, apostilas de orientação e apoio ao professor, videotapes, etc.); elaboração de artigos e comunicações; realização ou promoção de eventos \{ workshop interdisciplinar, fórum de debates, palestras, mostras de trabalhos de alunos, etc).

Ressaltam-se, também, neste momento a iniciativa e responsabilidade dos professores por todo o trabalho pertinente aos "miniprojetos" por disciplina curricular, desde a decisão sobre a sua natureza e a redação dos planos até a avaliação final e a elaboração de relatórios.

Refletindo sobre essa trajetória - e evidentemente não podemos generalizar as mudanças e os aprimoramentos a todos os participantes conseguimos entrever um processo subjacente às realizações e aos produtos acima arrolados, pertinente não só à prática pedagógica dos professores, mas a sua prática profissional como um todo. Tal processo parece assentar-se em três eixos básicos, intimamente imbricados: o propriamente pedagógico, relativo à produção/reprodução da prática em sala de aula; o da conquista da autonomia, referente às tomadas de decisão e à 
mobilização para a ação; e o da formação da identidade profissional, centrado na consciência gradual do papel profissional.

Arriscamo-nos, ainda, a conceber tal processo como uma hierarquia de níveis seqüenciais gradativamente "majorantes", que denominamos níveis de construção da profissionalidade docente, caracterizados como segue.

NÍVEL I —PRÁTICA REITERATIVA AUTOMATIZADA

Cabe aqui o conceito de "saber-fazer", descrito por Piaget para o caso da ação material. É também pertinente a figura do "professor-executor" de que fala Gimeno Sacristán (1988), enquanto gestor de tarefas planejadas previamente do exterior.

Neste nível, a prática diária mostra-se rígida e "fossilizada", reproduzindo-se por experiência vicária (ouvir dizer, ver fazer) ou por força da centração apenas nos resultados da ação (conseguir). E uma prática automatizada, no sentido de que não há consciência de que são aplicados os mesmos esquemas de atuação a situações, classes e contextos diferentes. Desnecessário salientar que predominam as práticas pedagógicas tradicionais, além do consumo acritico de manuais didáticos. A resistência à mudança é geral, embora sejam freqüentes os momentos de queixas, lamúrias e denúncias. A heteronomia também é traço marcante em todos os planos, anunciando-se, por exemplo, na obediência ou conformismo aos dispositivos burocráticos, aos conteúdos prescritos oficialmente e seqüenciados nos manuais, às (más) condições de trabalho, etc. A ausência de identidade profissional manifesta-se na aceitação ou conivência quanto aos desvios de função, no baixo grau de consciência do papel profissional e na negação ou omissão de responsabilidade pelo desempenho conseguido.

NÍVEL II —MOBILIDADE ESPONTÂNEA PONTUAL

As realizações neste nível estão bem próximas às da "prática criativa espontânea" sugerida por Vásquez (1986) para a práxis humana em 
geral, com alguns elementos da "reflexão-na-ação" de Schõn (apud Gómez, 1992). A figura do "professor-investigador" (Zeichner, 1992) também parece adequada, mas com algumas diferenças, como veremos.

A mobilidade que caracteriza este nível traduz-se pela quebra da resistência à mudança ou, pelo menos, pela consciência desta resistência. Mas a alteração da prática revela-se apenas "pontual", porque localizada, sem repercussões; e também espontânea, dada a ausência de orientação ou finalidade bem fundamentadas. Não há busca dos porquês dos resultados ou consequiências da ação realizada (do seu êxito ou fracasso, por exemplo). No aspecto propriamente pedagógico, observa-se a busca de alternativas ao ensino tradicional, particularmente no campo metodológico, mas sem a devida atenção aos fundamentos que dão suporte a tais mudanças, bem como à relação com um modelo educativo consistente. A ênfase na "mudança a qualquer preço" pode acompanhar-se da atitude maniqueísta de desvalorização absoluta do modelo tradicional de ensino. A heteronomia continua presente, principalmente com relação aos mecanismos burocráticos, embora já se insinuem questionamentos (das diretrizes curriculares oficiais, por exemplo), mas sem referencial claro para a tomada de posição. Quanto à formação da identidade profissional, há um início de autocrítica fundada na reflexão sobre o próprio trabalho e papel, que se mostra não só na capacidade de socializar as dificuldades sentidas, mas também na coragem de apontar as próprias falhas. As "choradeiras" persistem, mas agora em função das condições impeditivas às inovações ou da ansiedade quanto à culpabilidade sentida.

NÍVEL III-EXERCÍCIO PROFISSIONAL REFLETIDO OU PRÁTICA REFLETIDA

Nível em que se daria mais propriamente a compreensão decorrente da tomada de consciência de que fala Piaget (1977, 1978). Aproxima-se da "práxis criadora reflexiva" proposta por Vásquez (1986). Teria, também, elementos da "reflexão sobre a ação e sobre a reflexão-na-ação" descrita por Schõn (apud Gómez, 1992), mas com a ressalva de se acrescentar, à análise que o sujeito "realiza a posteriori sobre as características 
e os processos da sua pròpria ação" (op. cit., p. 105), aquela de natureza proativa (antecipação).

No plano pedagògico, este nível comporta, portanto, a análise da prática, do seu contexto e das condições impeditivas a uma mudança definida (não rnais "mudança qualquer"). A busca de mudanças pode voltar-se, agora, para a pesquisa de modelos educativos, de projetos pedagógicos rnais amplos, o que implica dimensão coletiva e trabalho interdisciplinar. A prática refletida mostra-se igualmente na consciência e na análise de como e por que as condições presentes constituem-se em barreiras à autonomia plena. As tomadas de decisão são baseadas na reflexão, anunciando a conquista da autonomia. Assim também, a autocrítica do próprio trabalho e papel se faz em função de modelos ideais de atuação, que servem como referencial inclusive para a criação e a experimentação de materiais didáticos alternativos. A criação de laços de compromisso com as necessidades educacionais dos alunos e com a escola enquanto instituição pode até mesmo descartar o espaço da sala de aula como lugar do exercício profissional.

Se esse exercício pudesse operar independente de condicionantes da realidade presente, arriscaríamos um Nível IV. Além da característica de autonomia profissional plena e de domínio coletivo, a epistemologia do professor não rnais seria implícita, mas elaborada num sistema coerente e consistente. O professor teria clara consciência de suas concepções epistemológicas e das implicações destas na prática, chegando até à elaboração do próprio currículo e do projeto pedagógico que julgasse apropriado. E, então, cairia por terra qualquer distância entre concepção e execução.

Antes de finalizarmos, são necessários alguns comentários e esclarecimentos em face desta proposta. E o principal diz respeito à generalização do processo, tal como caracterizado, a outras amostras de professores, sob condições semelhantes ou em situação escolar ordinária. Temos consciência, entretanto, de que isso só será possível mediante investigação rnais ampla, melhor sistematizada e acurada. 
$\mathrm{O}$ outro ponto refere-se a algumas figuras de professor que acentuamos. Talvez tenhamos desenhado imagens por demais rígidas, com isto minimizando a natureza ativa que pretendíamos explorar neste profissional. É bom lembrar o alerta de Gimeno Sacristán (1988), para quem a figura do "professor-executor" não é passiva, pois o professor é sempre mediador da relação entre o currículo e os alunos. Também não é uma figura totalmente destituída de autonomia. Esta se mostra na "tradução pedagógica" que faz o professor do conteúdo curricular, quando o acomoda a certas circunstâncias.

Assim também é ilusória a imagem do professor totalmente autônomo. Se a prática pedagógica é institucionalizada histórica, política e socialmente, o professor não pode selecionar, de forma voluntarista, as condições em que vai atuar.

Uma terceira observação diz respeito à natureza da construção que reivindicamos ao campo da profissionalidade docente. Antes de rnais nada, cabe justificar por que a seqüência proposta nos parece caracterizar uma hierarquia de níveis (ainda que talvez não de estruturas no sentido piagetiano), ao invés de "tipos profissionais". Salientamos, por exemplo, que a construção da prática docente não é um processo que começa do nada. Pode ser observado na sequiência o elemento de aperfeiçoamento progressivo, sendo fundamental a intervenção do fator tempo para dar ordem à sucessão apresentada. Isto não impede, entretanto, a ocorrência de estacionamento do profissional em um dado nível.

E também possível entrever duas faces ou vertentes nesse processo: construção de uma realidade (a pedagógica) e autoconstrução do agente educativo.

Tal como a vemos, a construção da profissionalidade docente comporta igualmente duas dimensões: a individual e a coletiva. $\mathrm{O}$ professor lida individualmente com condições únicas, que exigem tratamento singular. Neste caso, ele deve atribuir significado à realidade com que se depara, para que possa, inclusive, agir sobre ela. Dependendo de fatores 
ligados a sua formação e experiência, à interação que estabelece com situações mutáveis e com classes de alunos que nunca são as mesmas, cada professor desenvolve a sua "teoria", considerada como a rnais adequada para lidar naquele momento com aquela situação e classe específicas. Resulta daí que cada qual desenvolve um estilo próprio de atuação. Por outro lado, como em qualquer domínio, o professor que se inicia na profissão apropria-se da "cultura pedagógica" historicamente elaborada, dando-lhe continuidade ou imprimindo-lhe transformações. E isto não é possível ao indivíduo isolado, o que exige, então, a superação do trabalho solitário em favor da ação coletiva.

Por último, é necessário precisar as condições e os fatores responsáveis pelo processo acima. Vimos que é possível observar certos níveis nesse processo, mesmo sob condições desfavoráveis como as que apresenta a escola pública atual. Achamos que a experiência que relatamos dá exemplos suficientes de profissionais que se desenvolvem apesar das insuficiências e deficiências dos seus locais de trabalho.

Mas consideramos que o fator fundamental da construção da profissional idade docente encontra-se no exercício profissional coletivo numa situação essencialmente de cooperação (antes que de coação). Esta situação pode mesmo enfraquecer a dicotomia concepção-execução no campo do ensino.

Salientamos, enfim, que os resultados da nossa experiência com os professores da rede, aliás bastante rara no meio acadêmico, foram facilitados por um segundo fator aí presente: a estabilidade do grupo de participantes. Acreditamos que, se generalizados, a dimensão coletiva e o caráter estável de uma equipe de professores, com o auxílio de orientações especializadas, podem ser determinantes decisivos de mudanças educacionais rnais amplas e profundas, de mobilização política dos agentes do ensino e de criação de um projeto pedagógico consistente, coerente, e que ultrapasse o nível de mera proposta. 


\section{Referências bibliográficas}

CHAKUR, CR. de S.L. (Coord.). Prática Pedagógica: construindo, experimentando e avaliando o processo. Araraquara: FCLFUNDUNESP, 1993. Relatório de pesquisa.

Níveis de construção da profissional idade docente: um exemplo com professores de $5^{\mathrm{a}}$ a $8^{\mathrm{a}}$ série. In: Encontro Nacional de Didática e Prática de Ensino, 7, Goiânia, 1994. Anais... Goiânia: ENDIPE, 1994. p.121.

Trabalho docente nas séries finais do $\mathrm{I}^{\mathrm{s}}$ grau: um exemplo de construção coletiva da profissionalidade. DOXA. Revista Paulista de Psicologia e Educação, Araraquara.v.l, n.1, p. 115-28, 1995a.

CHAKUR, CR. de S.L. (Coord.). Os domínios social e não-social da cognição e a "lógica" das representações ideológicas. Cadernos de Pesquisa, São Paulo, n.95, p.63-72, 1995 b.

COLL, C, GILLIÉRON, C Jean Piaget: o desenvolvimento da inteligência e a construção do pensamento racional. In: LEITE, L.B. (Org.). Piaget e a escola de Genebra. São Paulo: Cortez, 1987.

DOLLE, J.M. Para além de Freud e Piaget: referenciais para novas perspectivas em psicologia. Petrópolis: Vozes, 1993.

GIMENO SACRISTÁN, J. El curriculum: una reflexión sobre la práctica. Madrid: Morata, 1988.

GÓMEZ. A.P. O pensamento prático do professor: a formação do professor como profissional reflexivo. In: NÓVOA, A. (Coord.). Os professores e a sua formação. Lisboa: Dom Quixote, 1992. 
INHELDER, B., SINCLAIR, H., BOVET, M. Aprendizagem e estruturas do conhecimento. São Paulo: Saraiva, 1977.

LA TAILLE, Y.de. Piaget, Vygotsky, Wallon: teorias psicogenéticas em discussão. São Paulo: Summus, 1992.

NÓVOA, A. (Coord.) Os professores e a sua formação. Lisboa: Dom Quixote, 1992.

PERRENOUD, P. Práticas pedagógicas, profissão docente e formação: perspectivas sociológicas. Lisboa: Dom Quixote, 1993.

PIAGET, J.et al. Biologia e conhecimento. Petrópolis: Vozes, 1973a. Problemas de psicologia genética. Rio de Janeiro: Forense, $1973 b$.

. Psicologia e epistemologia: por uma teoria do conhecimento. Rio de Janeiro: Forense, 1973c.

L'équilibration des structures cognitives: problème central du développement. Paris: PUF, 1975.

A tomada de consciência. São Paulo: Melhoramentos, 1977.

Fazer e compreender. São Paulo: Melhoramentos, 1978.

PIAGET, J., COLL, C.Recherches sur l'abstraction réfléchissante:, l'abstraction des relations logico-arithmétiques. Paris: PUF, 1977.

SCHÕN, D.A. Formar professores como profissionais reflexivos. In: NÓVOA, A. Os professores e a sua formação. Lisboa: Dom Quixote, 1992. VÁZQUEZ, A.S. Filosofia da práxis. 3 ed. Rio de Janeiro: Paz e Terra, 1986. 
ZEICHNER, K. Novos caminhos para o practicum: uma perspectiva para os anos 90. In: NÓVOA, A. (Coord.) Os professores e a sua formação. Lisboa: Dom Quixote, 1992.

Recebido em 22 de abril de 1996.

Cilene Ribeiro de Sá Leite Chakur é professora assistente do Departamento de Psicologia da Educação da Universidade Estadual Paulista (Unesp)/Campus de Araraquara.

This paper presents considerations about continue teachers formation aiming at in the long run, contributing to the proposition of a theory of the teacher's professional development based on the Piagetian constructivism. Some concepts and principles of this theoretical framework, especially those related to the awareness taking process, are reviewed, and the problems that are raised by a Piagetian reading of the teaching practice are discussed. It is finally proposed a hierarchy of the levels of the teacher's professionalism construction along the following axes: the pedagogical practice, the autonomy achievement, and the teacher's professional identity.

Le travail présente des réflexions sur la formation continue de l'enseignant et prétend, à long terme, contribuer à la formulation d'une théorie du développement professionnel de l'enseignant, fondée sur le constructivisme piagetien. Certains concepts et principes de ce courant sont revisés, en particulier ceux qui sont reliés au processus de la prise de conscience. Certains problèmes dérivés de la lecture piagetienne de la pratique de l'enseignant sont aussi discutés. Finalement, est proposée une hiérarchie de niveaux de construction du professionalisme de l'enseignant ayant comme axes la pratique pédagogique, la conquête de l'autonomie et l'identité professionnelle de l'enseignant. 
El trabajo plantea reflexiones sobre laformación continuada del profesor, visando, a largo plazo, contribuir hacia una teoría del desarrollo profesional docente basada en el constructivismo piagetiano. Se revisan algunos conceptos y principios de esa corriente, en particular aquellos relacionados al proceso de toma de conciencia, y se discuten problemas traedos por una lectura piagetiana de la práctica docente. Porfin, se propone una jerarquía de niveles de construcción de la profesionalidad docente, teniendo como ejes la práctica pedagógica, la conquista de la autonomia y la identidad profesional del profesor. 